\title{
elyra
}

\section{Nós também chegamos atrasadas para o prato principal}

\section{Érica Zingano / Charlotte Thiessen}

Érica Zíngano e Charlotte Thiessen passaram alguns dias da semana escrevendo em simultâneo: na agenda, marcaram horas para escrever ao mesmo tempo, mas em lugares diferentes da cidade. A partir desses encontros no tempo, começou-se um diálogo cruzado em silêncio, mas atravessado por imgs. 0 que se pode ler nessas imgs., também feitas de textos, senão os restos, os pedaços de vida que circulam e a qualquer momento podem simplesmente se levantar e caminhar a perder-nos de vista?

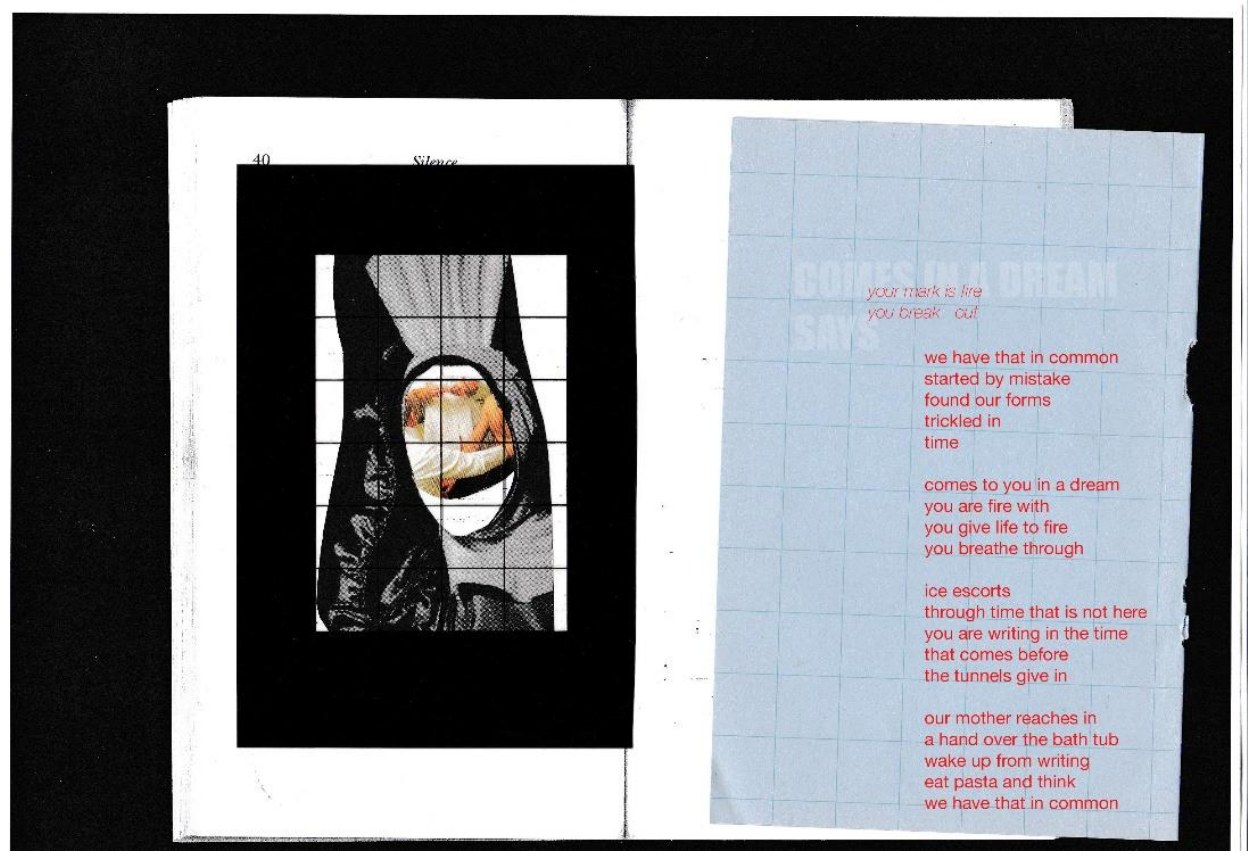



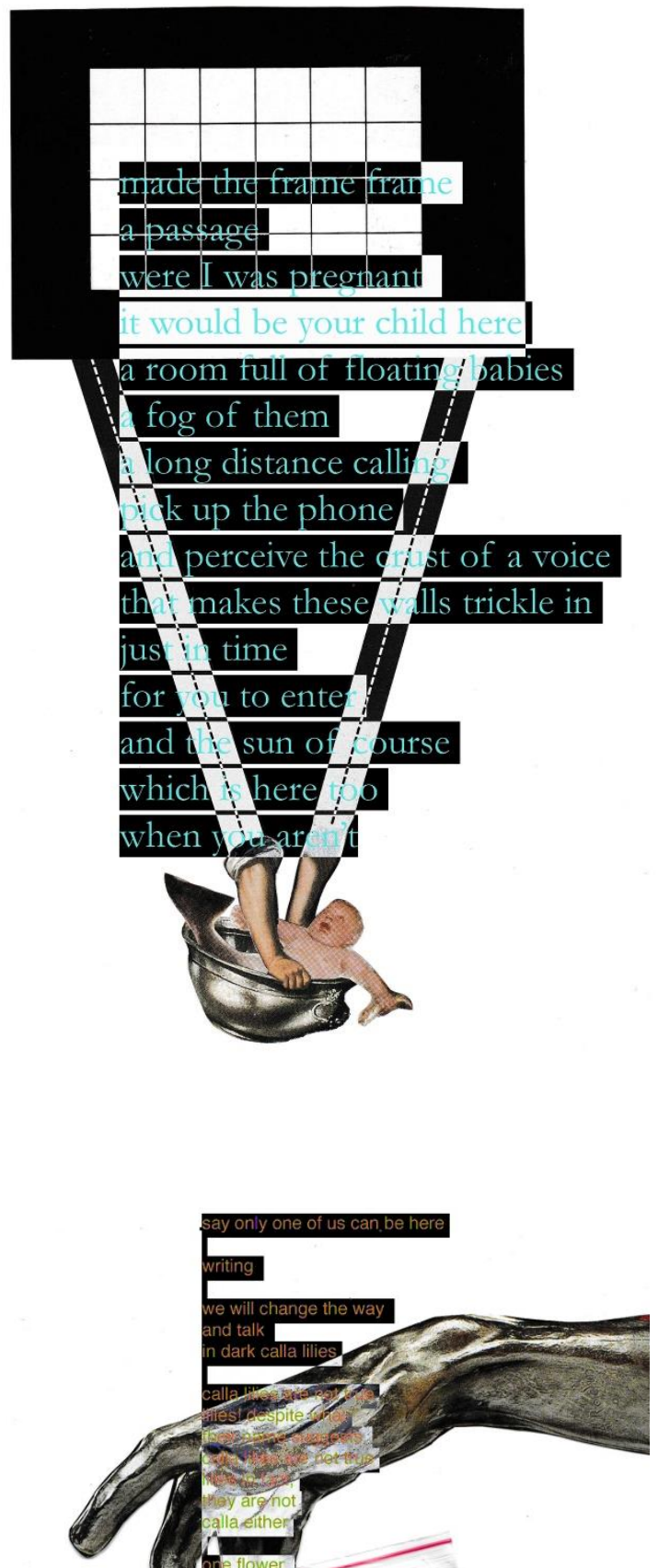

calla lithes en erenot true

lilies! despite what

their nan resugesests.

calla liliegarare irot true

lilies in fact,

they are not

calla either 

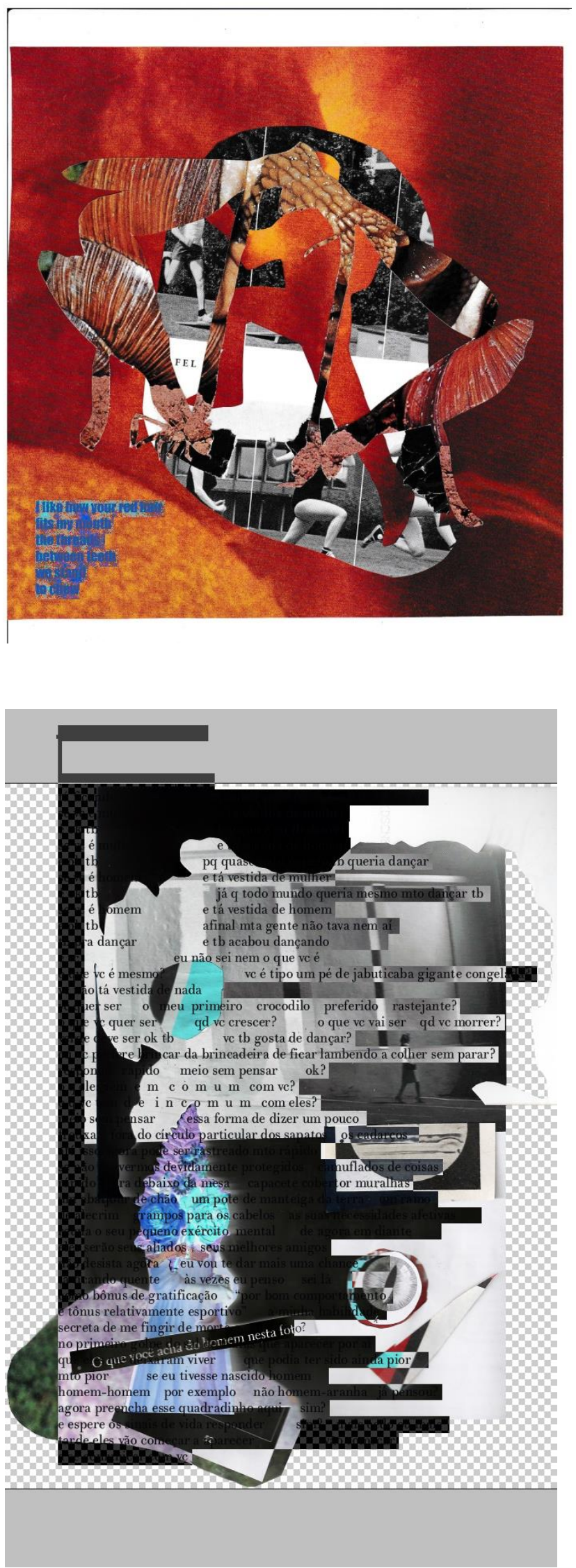


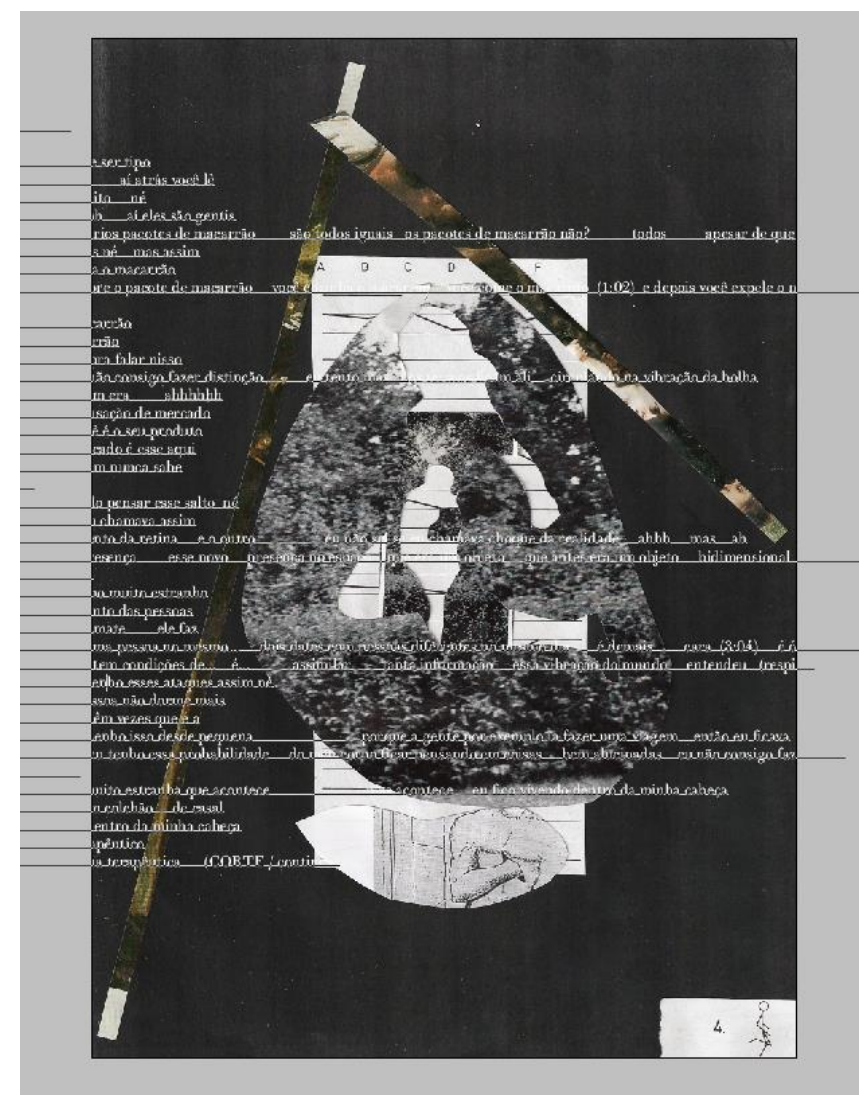

